\title{
Validation of the Chinese version of the CogState computerised cognitive assessment battery in Taiwanese patients with heart failure
}

\author{
Cheng-Chen Chou, Susan J Pressler, Bruno Giordani and Susan Jane Fetzer
}

\begin{abstract}
Aims and objectives. To evaluate the validity of the Chinese version of the CogState battery, a computerised cognitive testing among patients with heart failure in Taiwan. Background. Cognitive deficits are common in patients with heart failure and a validated Chinese measurement is required for assessing cognitive change for this population. The CogState computerised battery is a measurement of cognitive function and has been validated in many languages, but not Chinese.

Design. A cross-sectional study.

Methods. A convenience sample consisted of 76 women with heart failure and 64 healthy women in northern Taiwan. Women completed the Chinese version of the CogState battery and the Montreal Cognitive Assessment. Construct validity of the Chinese version of the battery was evaluated by exploratory factor analysis and known-group comparisons. Convergent validity of the CogState tasks was examined by Pearson correlation coefficients.

Results. Principal components factor analysis with promax rotation showed two factors reflecting the speed and memory dimensions of the tests. Scores for CogState battery tasks showed significant differences between the heart failure and healthy control group. Examination of convergent validity of the CogState found a significant association with the Montreal Cognitive Assessment.

Conclusion. The Chinese CogState Battery has satisfactory construct and convergent validity to measure cognitive deficits in patients with heart failure in Taiwan. Relevance to clinical practice. The Chinese CogState battery is a valid instrument for detecting cognitive deficits that may be subtle in the early stages, and identifying changes that provide insights into patients' abilities to implement treatment accurately and consistently. Better interventions tailored to the needs of the cognitive impaired population can be developed.
\end{abstract}

What does this paper contribute to the wider global clinical community?

- The validity of the Chinese version of the CogState computerised cognitive testing battery among Taiwanese people with heart failure were confirmed.

- Providing a useful and standardised measurement for assessing cognitive function in Chinesespeaking people with heart failure.

Key words: CogState computerised cognitive battery, heart failure, validation

Accepted for publication: 17 May 2015

Authors: Cheng-Chen Chou, PhD, RN, Assistant Professor, Department of Nursing, College of Medicine, National Cheng Kung University, Tainan, Taiwan; Susan J Pressler, PhD, RN, FAAN, FAHA, Professor, School of Nursing, University of Michigan, Ann Arbor; Bruno Giordani, PhD, Professor, School of Medicine, Neuropsychology Section, Department of Psychiatry, University of Michigan, Ann Arbor and Department of Neurology, University of Michigan, Ann
Arbor, MI; Susan Jane Fetzer, PhD, RN, Professor, Department of Nursing, University of New Hampshire, Durham, NH, USA Correspondence: Cheng-Chen Chou, Assistant Professor, Department of Nursing, College of Medicine, National Cheng Kung University, No. 1, University Road, Tainan 70101, Taiwan. Telephone: +886162353535 ext.5828.

E-mail: chenchou@mail.ncku.edu.tw 


\section{Introduction}

Heart failure (HF) is a major and growing problem worldwide and is associated with significant mortality and frequent hospitalisations (Gwadry-Sridhar et al. 2004). Cognitive deficits are common in patients with HF; prevalence ranges from 25-50\% among this population (Vogels et al. 2007, Pressler 2008). One of the most likely aetiologies of cognitive decline in $\mathrm{HF}$ is inadequate cerebral perfusion and cerebral hypoxia caused by low cardiac output (Bennett et al. (2005); Pullicino \& Hart 2001). Studies report that HF patients are at four times increased risk for cognitive deficits compared with matched controls (Sauvé et al. 2009). Qiu et al. (2006) have demonstrated that people with HF have twice the risk of dementia and Alzheimer disease over nine years.

Compared to healthy persons, patients with HF have shown cognitive deficits in areas including attention and concentration, memory, psychomotor speed and executive function (Bennett et al. 2005). Complaints of memory impairment are among the most frequently reported cognitive deficits in HF patients, affecting approximately $40 \%$ of them (Sauvé et al. 2009, Pressler et al. 2010b, Hawkins et al. 2012). Evidence supports that HF is associated with changes in brain structures which are critical for memory functioning. For example, HF patients had grey matter loss in brain areas involving cognition, including the prefrontal cortex areas critical to working memory (Woo et al. 2003). Brain injuries emerged in several areas in HF patients, including the hippocampus, fornix, thalamus, mammillary body and fornix fibres (Kumar et al. 2009, Woo et al. 2009), which serve important roles in episodic memory.

Empirical studies have consistently demonstrated the significant impacts of cognitive function on daily activities, HF self-care and mortality. For example, researchers reported verbal memory has been found to successfully explain performing instrumental activities of daily living (Hammers et al. 2013). The deficits in cognitive function may result in forgetfulness and poor learning ability that lead to failure to adhere to treatment regimens (Dickson et al. 2007). In a study among $166 \mathrm{HF}$ patients, cognitive deficits predicted 12-month mortality (Pressler et al. 2010a). Although cognitive deficits have consistently been reported by patients who suffer from HF, there are no generally accepted measures for cognitive screening in them.

\section{Background}

The CogState battery is a standardised, computerised cognitive test battery that was developed to measure cognitive function (Fredrickson et al. 2010). This test battery was selected because of its brevity, good usability, culture-free stimuli (i.e. playing cards). The general CogState battery is comprised of subset tasks to assess psychomotor speed, attention, working memory, visual and verbal memory, executive function and social cognition (Maruff et al. 2009). The battery has demonstrated sound psychometric properties. Testretest reliability has been shown to be satisfactory, with six days test-retest correlations in patients with coronary surgery ranging from 0.61-0.92. In a recent study, of HF patients in English, eight-week test-retest correlations ranged from 0.53-0.68 among $17 \mathrm{HF}$ patients (Hammers et al. 2013). Validity has been demonstrated between CogState tests and traditional neuropsychological measures with most of the correlations moderate to large (De Jager et al. 2009, Pietrzak et al. 2009, Yoshida et al. 2011). The CogState test battery significantly differentiates cognitive performance between persons with schizophrenia $(n=121)$ and matched participants in the control groups $(n=120)$ (Pietrzak et al. 2009). Stability is acceptable, with intra-class correlation coefficients over 12 months ranging from $0.65-0.91$ in older adults (Fredrickson et al. 2010). The battery identifies mild cognitive impairment with good sensitivity $(78 \%)$ and specificity $(90 \%$ ) among older adults (De Jager et al. 2009).

Evidence has shown that subsets of the CogState tasks are sensitive to cognitive changes in groups such as those with schizophrenia (Maruff et al. 2009, Pietrzak et al. 2009), mild traumatic brain injury (Maruff et al. 2009), dementia or Alzheimer's disease (Maruff et al. 2009, Hammers et al. 2012, Lim et al. 2012a), and mild cognitive impairment (Darby et al. 2002, De Jager et al. 2009). However, only one study with a small sample size evaluated the utility of the CogState verbal memory subset in an HF population (Hammers et al. 2013).

Given the high prevalence and importance of cognitive deficits in HF, the routine use of validated and brief, but sensitive, assessment instruments is needed for early detection of memory impairment in this population. The English CogState computerised battery has been translated in French, Korean (Lim et al. 2012b) and Japanese (Yoshida et al. 2011). The validation of the CogState tasks in a Chinese population has not yet been examined. Therefore, the purpose of this study was to evaluate the validity of the Chinese version of the CogState tests in Taiwanese patients with heart failure.

\section{Methods}

\section{Design}

A cross-sectional design recruited a convenience sample of 76 women with chronic HF and 64 age- and education- 
matched healthy women. The demographic and clinical information, the Montreal Cognitive Assessment (MoCA) and the Chinese computerised CogState battery were used to collect data through interview and medical records.

\section{Setting and participants}

The study was conducted in northern Taiwan during November 2010 through October 2011. Women were eligible if they were age 50 years and older, their last menstrual cycle was completed more than 12 months previously, and could read and speak Mandarin, with HF had the diagnosis at least six months while healthy women, no major medical diagnoses. Exclusion criteria included any conditions known to cause cognitive deficits or the presence of impaired sensory problems. Women with hypertension and a blood pressure $<140 / 90 \mathrm{mmHg}$ or hyperlipidemia with cholesterol less than $200 \mathrm{mg} / \mathrm{dl}$ were placed in the healthy group.

\section{Measures}

\section{Demographic and clinical information}

This questionnaire was design to collect demographic and HF information of the participants, including data of age, education, marital status, employment, oestrogen replacement therapy, comorbidity number, blood pressure and NYHA functional class.

\section{CogState Computerised Cognitive Assessment Battery}

The tasks in the Chinese version of CogState battery were translated from the English version into Chinese and made available by CogState Company (http://cogstate.com/) using a linguistically validated process to produce an instrument that is conceptually equivalent to the English version. The CogState validation process included seven steps: conceptual definition, forward translation, backward translation, pilot testing, international harmonisation, proofreading and reporting (MAPI Institute, 2011). Six tasks of the CogState were selected for validation.

Two CogState tasks measuring psychomotor speed and attention were evaluated. The Detection task (DET) is a psychomotor speed task that requires participants to respond as soon as possible when a playing card in the centre of the computer screen flips over. The Identification task (IDN) is a measure of visual attention that assesses speed of performance. Participants are asked to press the 'yes' button as soon as possible if the card in the centre of the computer screen is red and the 'no' button if the card is black (Collie et al. 2007). The task ends when 30 correct trials have been completed. A lower score indicated better performance.

Working memory was measured by The One Back Task (OBK). The OBK is a measure of working memory that assesses accuracy of performance. The participant presses the 'yes' button if a playing card is the same as the immediately previous card and the 'no' button if the card is different (Cysique et al. 2006). Thirty correct trials are required for completion. A higher score indicates better performance.

Verbal memory was measured by International Shopping List Task (ISLT), which included 3 trials of immediate free recall of a series of 12-word lists, followed by 20-minute delayed recall of the word list. The individuals are required to remember a list of shopping items that are relevant to their culture. Studies have reported that performance is equivalent among English, French and Malaysian versions of the ISLT (Lim et al. 2009). The ISLT has been shown to correlate with the Hopkins Verbal Learning Test-Revised (HVLT-R) $(r=0.47$ to 0.75$)$ and had adequate stability in patients with chronic HF $(r=0.53$ to 0.68$)$ (Hammers et al. 2013). Possible scores range from $0-36$ in the ISLT first three trials and $0-12$ in the delay recall ISLT. A higher score indicates better verbal memory performance.

Visual memory was measured by the One Card Learning Task (OCL) and the Continuous Paired Associate Learning Task (CPAL). The OCL assesses accuracy of performance. Similar in presentation to the OBK, the participants press the 'yes' button if the card has appeared before or the 'no' button if it has not appeared. The OCL ends after 42 trials are completed (Fredrickson et al. 2010). A higher score indicates a better performance. The CPAL requires participants to learn sets of pattern-location associations in acquisition and learning phases. In the first phase, the participant is asked to remember the identical shape patterns hidden beneath peripheral locations. In the learning phase, each pattern is presented in the centre of the screen and the participant is required to select the correct pattern presented in the peripheral location (O'Donnell et al. 2011). It is scored as the total number of errors across seven rounds, with lower scores indicating better visual memory performance.

\section{Montreal Cognitive Assessment (MoCA)}

The Montreal Cognitive Assessment (MoCA) was used to measure global cognitive function and test construct validity of the CogState. It was developed by Nasreddine et al. (2005) as a screening tool for mild cognitive impairment (MCI) and early dementia. The MoCA is a 10-minute test and includes items on visual spatial abilities, naming, shortterm memory recall, attention, language, verbal abstraction, 
memory and orientation. The MoCA was selected as a measure of global cognitive function because it has been demonstrated to be more sensitive in detecting cognitive impairment in HF patients than another commonly used instrument, the Mini-Mental Status Examination (MMSE) (Athilingam et al. 2011). Possible MoCA scores range from 0-30; higher scores indicate better global cognitive function. Using a cut-off score of 26 to identify MCI, a sensitivity of $90 \%$ and a specificity of $87 \%$ were found among 93 patients with mild Alzheimer's disease (AD) and 90 healthy older controls in the original study in Canada (Nasreddine et al. 2005). The criterion validity, internal consistency and test-retest reliability were satisfactory in the Chinese version of MoCA (Wong et al. 2009).

\section{Data collection and procedures}

After obtaining approval from the Institutional Review Board of the University of Michigan, and the Tri-Service General Hospital in Taipei, Taiwan, the investigator approached potential participants at the cardiovascular, gynaecology and women's health centre clinics who met inclusion criteria. Written informed consent was obtained and data were collected by face-to-face interviews. Data collection required 60-90 minutes. Demographic and clinical information was collected using questionnaires and from the medical record. The MoCA and the computerised CogState tests were administered by the researcher who had been trained by a neuropsychologist.

\section{Statistical Analysis}

Using SPSS version 17.0 software (Statistical Package for Social Sciences, Inc., Chicago, IL, USA), descriptive statistics were used to summarise demographic and clinical variables, scores for CogState computerised tasks and MoCA results. Student's $t$-tests, chi-square tests and Fisher's exact tests were used to examine differences between groups.

The factor structure of the CogState tasks was determined by performing exploratory factor analysis using principal components analysis with varimax rotation. The KaiserMeyer-Olkin (KMO) test and Bartlett's test of sphericity were used to examine sampling adequacy and model appropriateness for performing factor analyses. Criteria used for factor extraction included having eigenvalues greater than 1 , factor loadings higher than 0.30 and interpretability (Field 2005). Analysis of covariance (ANCOVA) was used for each subset of the CogState battery (DET, IDN, ONB, ISLT, ISLT-DR, OCL and CPAL) to compare differences in means adjusting for age and education between the HF and healthy group. Convergent validity was examined by calculating Pearson correlation coefficients for CogState tasks (DET, IDN, ONB, ISLT, ISLT-DR, OCL and CPAL) and the MoCA.

\section{Results}

\section{Sample characteristics}

The sample included 76 women with HF and 64 healthy women. In HF group, the mean age of the subjects was 69.7 years $(S D=10 \cdot 2)$ (Table 1$)$. The education matched educational level was $7 \cdot 3$ years $(\mathrm{SD}=3 \cdot 3)$. The majority of participants were married $(80.3 \%)$ and were not employed $(92.1 \%)$. Women with $\mathrm{HF}$ had significantly higher systolic blood pressures and more comorbid diseases compared to healthy women. Moreover, most women with HF were in New York Heart Association (NYHA) class II $(75 \%)$.

\section{Exploratory factor analysis}

Exploratory factor analysis using principal components analysis was performed to determine the number and the content of factors underlying the CogState tasks. The Kaiser-Meyer-Olkin test measure for the data was 0.724 , indicating sampling adequacy and compact patterns of correlation; the factor analysis produced distinct and reliable factors (Field 2005). Bartlett's test of sphericity reached statistical significance $(p<0.001)$, which supported that relationships between the variables existed (Field 2005). Oblique promax rotations were applied as the CogState factors were assumed to be correlated. Factor analysis showed the presence of two factors with eigenvalues $>1$, explaining $64.6 \%$ of the total variance (Table 2 ). The first factor accounted for $44.95 \%$ of the total variance and contained OBK, ISLT, ISLT-DR, OCL, and CPAL and was labelled 'memory', with factor loadings ranging $0 \cdot 61-0 \cdot 81$. The second factor accounted for $19.69 \%$ of the total variances and contained two-subset tasks (DET and IDN) and was labelled 'speed'. Factor loadings ranged from 0.900.91 .

\section{Construct validity}

A group comparison analysis was conducted to see how well CogState tasks discriminated among the two groups of women who differed in terms of their HF diagnosis (Table 3). The ANCOVA resulted in statistically significant differences $(p<0.05)$ for CogState scores between the HF 
Table 1 Demographic information of sample

\begin{tabular}{|c|c|c|c|}
\hline Characteristics & $\mathrm{HF}(n=76)$ & Health $(n=64)$ & $p$-Value \\
\hline Age, mean \pm SD & $69 \cdot 7 \pm 10 \cdot 2$ & $68 \cdot 9 \pm 7 \cdot 1$ & $0 \cdot 59$ \\
\hline \multicolumn{4}{|l|}{ Marital status, $n(\%)$} \\
\hline Married & $61(80 \cdot 3)$ & $41(64 \cdot 1)$ & \multirow[t]{4}{*}{$0 \cdot 16$} \\
\hline Single & $1(1 \cdot 3)$ & $2(3 \cdot 0)$ & \\
\hline Divorced & $2(2 \cdot 6)$ & $4(6 \cdot 3)$ & \\
\hline Widowed & $12(15 \cdot 8)$ & $17(26 \cdot 6)$ & \\
\hline Education, mean \pm SD & $7 \cdot 3 \pm 3 \cdot 3$ & $8 \cdot 0 \pm 3 \cdot 1$ & $0 \cdot 19$ \\
\hline \multicolumn{4}{|l|}{ Employment, $n(\%)$} \\
\hline No & $70(92 \cdot 1)$ & $45(70 \cdot 3)$ & \multirow[t]{2}{*}{$0 \cdot 001 * *$} \\
\hline Yes & $6(7 \cdot 9)$ & $19(29.7)$ & \\
\hline Systolic blood pressure, mean \pm SD & $135 \cdot 5 \pm 17 \cdot 5$ & $122 \cdot 3 \pm 9 \cdot 5$ & $<0.001 * * *$ \\
\hline Diastolic blood pressure, mean $\pm \mathrm{SD}$ & $76 \cdot 1 \pm 10 \cdot 2$ & $74.4 \pm 6 \cdot 9$ & $0 \cdot 27$ \\
\hline Comorbidity number, mean \pm SD & $1 \cdot 8 \pm 0 \cdot 9$ & $0 \cdot 2 \pm 0.4$ & $<0.001 * * *$ \\
\hline \multicolumn{4}{|l|}{ NYHA class, $n(\%)$} \\
\hline Class I & $6(7 \cdot 9)$ & & \\
\hline Class II & $57(75)$ & & \\
\hline Class III & $11(14 \cdot 5)$ & & \\
\hline Class IV & $2(2 \cdot 6)$ & & \\
\hline
\end{tabular}

HF, heart failure; NYHA, New York Heart Association

$* p<0.05, * * p<0.01, * * * p<0.001$.

Table 2 Principal components analysis of CogState tests in the HF group $(n=76)$

\begin{tabular}{lcr}
\hline & \multicolumn{2}{l}{ Factor loadings } \\
\cline { 2 - 3 } & Factor 1 & Factor 2 \\
\hline Factor 1: Memory & & \\
One Back, accuracy (OBK) & 0.81 & -0.08 \\
International Shopping List, total (ISLT) & 0.71 & 0.27 \\
International Shopping List, & 0.77 & 0.24 \\
$\quad$ delayed recall (ISLT-DR) & & \\
One Card Learning, accuracy (OCL) & 0.74 & -0.39 \\
Continuous Paired Associate & 0.61 & 0.07 \\
$\quad$ Learning, error (CPAL) & & \\
Factor 2: Speed & & \\
$\quad$ Detection task & -0.03 & 0.90 \\
Identification task & -0.05 & 0.91 \\
$\quad$ Eigenvalue & 3.15 & 1.38 \\
$\quad$ Explained variance & 44.95 & 19.69 \\
$\quad$ Cumulative variance & 44.95 & 64.64 \\
Total CogState tests & & \\
\hline
\end{tabular}

HF, heart failure; Kaiser-Meyer-Olkin (KMO) test measure of sampling adequacy $=0.724$; Bartlett's test of sphericity $p<0.001$.

and healthy groups. Women with HF reported higher psychomotor speed score than did healthy women (DET, $p<0.01)$ and lower scores on working memory (OBK, $p<0.05$ ) and verbal memory tasks (ISLT, $p<0.001$; ISLTDR, $p<0.001)$, after controlling for age and education years, providing evidence that further supported the construct validity of the CogState battery.

\section{Convergent validity}

The relationship between each individual test score of the CogState and MoCA are presented in Table 4. Significant correlations were also shown between the MoCA scores are subset tasks of the CogState. These findings demonstrate convergent validity of the CogState.

\section{Discussion}

This is the first study to report use of the Chinese version of a computerised cognitive test battery in an HF population. Results supported the hypothesis that the Chinese CogState subtests demonstrated good construct validity and convergent validity among Taiwanese HF patients.

Findings of the exploratory factor analysis pointed to the common features of the selected CogState battery tasks, namely speed and memory, which support construct validity of the selected CogState battery items in this population. The OBK, OCL and CPAL present visual stimuli in the centre of the computer, and participants must memorise presentations to perform adequately. The ISLT, on the other hand, provides verbal stimuli that participants need to recall immediately or later and performance is based on how many words can be recalled correctly. For the remaining measures, such as DET and IDN, although the visual stimuli are presented in the middle of the computer screen, the participants are required to respond as quickly as possible. Four tasks loaded on the factor labelled as memory, 
Table 3 Group comparison for CogState subset tasks

\begin{tabular}{|c|c|c|c|c|}
\hline & $\begin{array}{l}\mathrm{HF}(n=76) \\
\text { mean } \pm \mathrm{SD}\end{array}$ & $\begin{array}{l}\text { Health }(n=64) \\
\text { mean } \pm S D\end{array}$ & F & $p$ \\
\hline Detection, speed & $2 \cdot 7 \pm 0 \cdot 1$ & $2 \cdot 6 \pm 0 \cdot 1$ & $7 \cdot 6$ & $0 \cdot 007 * *$ \\
\hline Identification, speed & $2 \cdot 7 \pm 0 \cdot 1$ & $2 \cdot 7 \pm 0 \cdot 0$ & $0 \cdot 2$ & $0 \cdot 65$ \\
\hline One Back, accuracy & $1 \cdot 0 \pm 0 \cdot 2$ & $1 \cdot 1 \pm 0 \cdot 1$ & $4 \cdot 3$ & $0 \cdot 04 *$ \\
\hline International Shopping List, total & $20 \cdot 2 \pm 5 \cdot 7$ & $23 \cdot 4 \pm 4 \cdot 4$ & $14 \cdot 7$ & $<0 \cdot 001 * * *$ \\
\hline International Shopping List, delayed recall & $6 \cdot 8 \pm 2 \cdot 8$ & $8 \cdot 3 \pm 1 \cdot 9$ & $13 \cdot 9$ & $<0 \cdot 001 * * *$ \\
\hline One Card Learning, accuracy & $0 \cdot 9 \pm 0 \cdot 1$ & $0 \cdot 9 \pm 0 \cdot 1$ & $3 \cdot 6$ & 0.06 \\
\hline Continuous Paired Associate Learning, error & $96 \cdot 7 \pm 61 \cdot 3$ & $79 \cdot 3 \pm 40 \cdot 3$ & $2 \cdot 8$ & $0 \cdot 10$ \\
\hline
\end{tabular}

$\mathrm{HF}$, heart failure.

$p$-Value for analysis covariance adjusting for age and education.

$* p<0.05 * * p<0.01 * * * p<0.001$.

Table 4 Pearson's product-moment correlations between CogState tests and MoCA

\begin{tabular}{|c|c|c|c|}
\hline \multirow[b]{2}{*}{ CogState Tests } & \multicolumn{3}{|l|}{ MoCA } \\
\hline & HF group & $\begin{array}{l}\text { Healthy } \\
\text { group }\end{array}$ & Totals \\
\hline Detection task & -0.186 & $0 \cdot 017$ & $-0 \cdot 208 *$ \\
\hline Identification task & -0.208 & $-0 \cdot 115$ & $-0 \cdot 191 *$ \\
\hline One Back task & $0.417 * * *$ & $0.526 * * *$ & $0.472 * * *$ \\
\hline $\begin{array}{l}\text { International } \\
\text { Shopping List Task }\end{array}$ & $0.565 * * *$ & $0.582 * * *$ & $0 \cdot 610 * * *$ \\
\hline $\begin{array}{l}\text { International Shopping } \\
\text { List Task: delayed recall }\end{array}$ & $0 \cdot 640 * * *$ & $0 \cdot 647 * * *$ & $0 \cdot 676 * *$ \\
\hline One Card Learning Test & $0.395 * *$ & $0.330 * *$ & $0.404 * *$ \\
\hline $\begin{array}{l}\text { Continuous Paired } \\
\text { Associate Learning Task }\end{array}$ & $-0 \cdot 396^{* *}$ & $-0.408 * *$ & $-0.421 * * *$ \\
\hline
\end{tabular}

MoCA, Montreal Cognitive Assessment; HF, heart failure.

${ }^{*} p<0.05, * * p<0.01, * * * p<0.001$.

which included working memory (OBK) and episodic memory tasks (OCL, ISLT and CPAL). The findings are similar to those of Yoshida et al. (2011), who conducted a factor analysis for the CogState Schizophrenia Battery in 40 Japanese patients. In our study, however, OBK was included in the memory factor, while Yoshida et al. (2011) found the OBK was not associated with any factor solution. The small sample size of the Japanese study $(n=40)$ may explain the findings.

Results showed that HF patients scored significantly lower than the healthy controls group, which is consistent with previous findings using other standard neuropsychological tests (Sauvé et al. 2009, Pressler et al. 2010b). Women who have HF are more likely to demonstrate poor performance on most of the CogState memory tasks when compared to a healthy female control group. Although CPAL task results were not significantly different in the two groups, the HF group had more CPAL errors compared to the control group. These results are congruent with findings that HF patients show increased injury in brain regions associated with the working memory system (Woo et al. 2003) as well as in brain regions associated with episodic memory (Kumar et al. 2009, Woo et al. 2009).

The Chinese CogState subtests were significantly correlated with MoCA is the Chinese sample. The MoCA evaluates different cognitive abilities, including memory (Nasreddine et al. 2005), thus these results provided evidence that supports validity of the Chinese CogState subtests. The English version of the selected CogState tests (DET, IDN, OBK, ISLT) was significantly correlated with standard neuropsychological tests and only ISLT was significantly correlated with MMSE in a small HF sample $(n=40)$ (Hammers et al. 2013). Interesting, no association was found between the global cognitive measure (MMSE or MoCA) with DET or IDN in this current study or previous HF study (Hammers et al. 2013). This finding may be explained as the DET and IDN are measures of psychomotor speed and the MMSE or MoCA did not measure any speed of response. The current study found that memory subtests such as OBK, ISLT, OCL and CPAL had significant correlations with a global cognitive measure (MoCA). Compared to MMSE, the MoCA is a sensitive cognitive screening measure that can identify possible MCI in patients with HF (Cameron et al. 2012). Future study is needed to compare correlations among the Chinese CogState subtests using standard neuropsychological tests in the HF population.

There are some limitations of the study. Although the study did not evaluate test-retest reliability of the Chinese CogState, other studies have reported acceptable test-retest reliability for its subtests in non-Chinese older adults (Fredrickson et al. 2010). Future study is needed to evaluate test-retest reliability of the Chinese CogState. In addition, some participants with less computer experience required more time and practice before they feel comfortable to complete the tasks. Use of a 
laptop with a touch screen is suggested for future studies. Another limitation is that participants included only women with HF. It is not clear whether these results would be the same for men or for other chronic diseases.

\section{Conclusion}

This study demonstrated that the Chinese CogState Computerized Cognitive Assessment Battery has satisfactory construct and convergent validity to measure cognitive deficits in patients with HF in Taiwan. We recommend the Chinese CogState subtests to be compared to more standard neuropsychological tests.

\section{Relevance to clinical practice}

As clinicians have a better understanding of cognitive deficit patterns in patients with HF and other chronic diseases is important that they provide improved care and treatment. Nurses play a critical role in assisting patients to plan longterm treatments towards the goal of successful living. The CogState battery could be used to help detect cognitive defi- cits that may be subtle in the early stages, and identify changes that provide insights into patients' abilities to implement treatment accurately and consistently. Better interventions tailored to the needs of the cognitive impaired population can be developed.

\section{Acknowledgements}

Manuscript reviewing was provided by Babara Therrien, $\mathrm{PhD}$, University of Michigan School of Nursing, and Jacqui Smith, PhD, University of Michigan Department of Psychology.

\section{Contributions}

Study design: CCC, SJP; data collection and data analysis: CCC, SJP, BG and manuscript preparation: CCC, SJP, BG, SJF.

\section{Conflict of Interest}

None.

\section{References}

Athilingam P, King KB, Burgin SW, Ackerman M, Cushman LA \& Chen L (2011) The Montreal Cognitive Assessment and Mini-Mental Status Examination compared as cognitive screening tools in heart failure. Heart and Lung 40, 521-529.

Bennett SJ, Sauvé MJ \& Shaw RM (2005) A conceptual model of cognitive deficits in chronic heart failure. Journal of Nursing Scholarship 37, 222-228.

Cameron J, Worrall-Carter L, Page K, Stewart S \& Ski CF (2012) Screening for mild cognitive impairment in patients with heart failure: Montreal Cognitive Assessment versus Mini Mental State Exam. European Journal of Cardiovascular Nursing 12, 252-260.

Collie A, Darekar A, Weissgerber G, Toh M, Snyder P, Maruff P \& Huggins J (2007) Cognitive testing in early-phase clinical trials: development of a rapid computerized test battery and application in a simulated Phase I study. Contemporary Clinical Trials 28, 391-400.
Cysique L, Maruff P, Darby D \& Brew B (2006) The assessment of cognitive function in advanced HIV-1 infection and AIDS dementia complex using a new computerized cognitive test battery. Archives of Clinical Neuropsychology 21, 185-194.

Darby D, Maruff P, Collie A \& McStephen M (2002) Mild cognitive impairment can be detected by multiple assessments in a single day. American Academy of Neurology 59, 1042-1046.

De Jager CA, Schrijnemaekers MC, Honey EM \& Budge MM (2009) Detection of MCI in the clinic: evaluation of the sensitivity and specificity of a computerized test battery, the Hopkins verbal learning test and the MMSE. Age and Ageing 38, 455-460.

Dickson VV, Tkacs N \& Riegel B (2007) Cognitive influence on self-care decision making in persons with heart failure. American Heart Journal 154, 424-431.

Field A (2005) Discovering Statistics Using SPSS. Sage Publication, London.
Fredrickson J, Maruff P, Woodward M, Moore L, Fredrickson A, Sach J \& Darby D (2010) Evaluation of the usability of a brief computerized cognitive screening test in older people for epidemiological studies. Neuroepidemiology 34, 65-75.

Gwadry-Sridhar FH, Flintoft V, Lee DS, Lee H \& Guyatt GH (2004) A systematic review and meta-analysis of studies comparing readmission rates and mortality rates in patients with heart failure. Archives of Internal Medicine 164, 2315-2320.

Hammers DB, Jung M, Pressler SJ, Sullivan BJ, Koelling T \& Giordani B (2013) Clinical utility of auditory memory testing in a heart failure population. The Journal of Cardiovascular Nursing 28, 444-452.

Hammers D, Spurgeon E, Ryan K, Persad C, Barbas N, Heidebrink J, Darby D \& Giordani B (2012) Validity of a brief computerized cognitive screening test in dementia. Journal of Geriatric Psychiatry and Neurology, 25, 89-99. 
Hawkins LA, Kilian S, Firek A, Kashner TM, Firek CJ \& Silvet H (2012) Cognitive impairment and medication adherence in outpatients with heart failure. Heart and Lung 41, 572-582.

Kumar R, Woo MA, Birrer BV, Macey PM, Fonarow GC, Hamilton MA \& Harper RM (2009) Mammillary bodies and fornix fibers are injured in heart failure. Neurobiology of Disease 33, 236-242.

Lim YY, Prang KH, Cysique L, Pietrzak RH, Snyder P \& Maruff P (2009) A method for cross-cultural adaptation of a verbal memory assessment. Behavior Research Methods 41, 1190-1200.

Lim YY, Ellis KA, Harrington K, Ames D, Martins RN, Masters CL, Rowe C, Savage G, Szoeke C, Darby D, Maruff $\mathrm{P} \&$ the AIBL Research Group (2012a) Use of the CogState Brief Battery in the assessment of Alzheimer's disease related cognitive impairment in the Australian Imaging, Biomarkers and Lifestyle (AIBL) study. Journal of Clinical and Experimental Neuropsychology, 34, 345-358.

Lim YY, Pietrzak RH, Snyder PJ, Darby D \& Maruff P (2012b) Preliminary data on the effect of culture on the assessment of Alzheimer's disease-related verbal memory impairment with the International Shopping List Test. Archives of Clinical Neuropsychology 27, 136-147.

MAPI Institute (2011) Methodology. Available at: http://www.mapi-institute. com/linguistic-validation/methodology (accessed 27 May 2011).

Maruff P, Thomas E, Cysique L, Brew B, Collie A, Snyder P \& Pietrzak RH (2009) Validity of the CogState brief battery relationship to standardized tests and sensitivity to cognitive impairment in mild traumatic brain injury schizophrenia and AIDS dementia complex. Archives of Clinical Neuropsychology 24, 65-78.
Nasreddine ZS, Phillips NA, Bédirian V, Charbonneau S, Whitehead V, Collin I, Cummings JL \& Chertkow H (2005) The Montreal Cognitive Assessment (MoCA): a brief screening tool for mild cognitive impairment. Journal of the American Geriatrics Society, 53, 695-699.

O’Donnell J, Pietrzak RH, Ellis KC, Snyder PJ \& Maruff P (2011) Understanding failure of visual paired associate learning in amnestic mild cognitive impairment. Journal of Clinical and Experimental Neuropsychology 33, 1069-1078.

Pietrzak RH, Olver J, Norman T, Piskulic D, Maruff P \& Snyder PJ (2009) A comparison of the CogState schizophrenia battery and the measurement and treatment research to improve cognition in schizophrenia (MATRICS) battery in assessing cognitive impairment in chronic schizophrenia. Journal of Clinical and Experimental Neuropsychology 31, 848-859.

Pressler SJ (2008) Cognitive functioning and chronic heart failure: a review of the literature (2002-July 2007). The Journal of Cardiovascular Nursing 23, 239-249.

Pressler SJ, Kim J, Riley P, Ronis DL \& Gradus-Pizlo I (2010a) Memory dysfunction, psychomotor slowing, and decreased executive function predict mortality in patients with heart failure and low ejection fraction. Journal of Cardiac Failure 16, 750-760.

Pressler SJ, Subramanian U, Kareken D, Perkins SM, Gradus-Pizlo I, Sauve MJ, Ding Y, Kim J, Sloan R, Jaynes H \& Shaw RM (2010b) Cognitive deficits in chronic heart failure. Nursing Research, 59, 127-139.

Pullicino PM \& Hart J (2001) Cognitive impairment in congestive heart failure? Embolism vs hypoperfusion. Neurology 57, 1945-1946.

Qiu C, Winblad B, Marengoni A, Klarin I, Fastbom J \& Fratiglioni L (2006)
Heart failure and risk of dementia and Alzheimer disease a population based cohort study. Archives of Internal Medicine 166, 1003-1008.

Sauvé MJ, Lewis WR, Blankenbiller M, Rickabaugh B \& Pressler SJ (2009) Cognitve impairments in chronic heart failure: a case controlled study. Journal of Cardiac Failure 15, 1-10.

Vogels RL, Oosterman JM, van Harten B, Scheltens P, van der Flier WM, Schroeder-Tanka JM \& Weinstein HC (2007) Profile of cognitive impairment in chronic heart failure. Journal of the American Geriatrics Society 55, 1764 1770.

Wong A, Xiong YY, Kwan PW, Chan AY, Lam WW, Wang K, Chu WC, Nyenhuis DL, Nasreddine Z, Wong LK \& Mok VC (2009) The validity, reliability and clinical utility of the Hong Kong Montreal Cognitive Assessment (HK-MoCA) in patients with cerebral small vessel disease. Dementia and Geriatric Cognitive Disorders, 28, 8187.

Woo MA, Macey PM, Fonarow GC, Hamilton MA \& Harper RM (2003) Regional brain gray matter loss in heart failure. Journal of Applied Physiology 95, 677-684.

Woo MA, Kumar R, Macey PM, Fonarow GC \& Harper RM (2009) Brain injury in autonomic, emotional, and cognitive regulatory areas in patients with heart failure. Journal of Cardiac Failure 15, 214-223.

Yoshida T, Suga M, Arima K, Muranaka Y, Tanaka T, Eguchi S, Lin C, Yoshida S, Ishikawa M, Higuchi Y, Seo T, Ueoka Y, Tomotake M, Kaneda Y, Darby D, Maruff P, Iyo M, Kasai K, Higuchi T, Sumiyoshi T, Ohmori T, Takahashi K \& Hashimoto K (2011) Criterion and construct validity of the CogState Schizophrenia Battery in Japanese patients with schizophrenia. PLoS ONE, 6, e20469. 